\title{
Spinocerebellar ataxia type 26
}

INSERM

\section{Source}

INSERM. (1999). Orphanet: an online rare disease and orphan drug data base.

Spinocerebellar ataxia type 26. ORPHA:101112

Spinocerebellar ataxia type 26 (SCA26) is a very rare subtype of autosomal dominant cerebellar ataxia type III (ADCA type III; see this term) characterized by late-onset and slowly progressive cerebellar signs (gait ataxia) and eye movement abnormalities. 